\title{
Implementing an Electronic Notebook in Science
}

\author{
Mark Edwards \\ University of Greenwich, School of Science
}

\section{Introduction}

Professor John Ziman spent time considering science and its relationship with society, in terms of what it is, how it works, what it means, how reliable it might be, what should be taught, who should teach it and to whom (Ziman, 1968, 1991, 2002, 2008). I do not intend to further such an esteemed body of work, because, if I can paraphrase one of Ziman's statements (Ziman, 1991), science is such a complex activity, so much part of our civilization, so rapidly changing in form and content that it cannot be presented in a few simple sentences. I want to take just one material and technological mode of science (another descriptive phrase of Ziman's, see later) and discuss how important one tool is within this mode, as a foundation to high quality manufacturing in the global and highly competitive world of the pharmaceutical industry. The tool I wish to introduce and then elaborate on is the laboratory hard-backed, notebook and later, in its more modern form, the electronic laboratory notebook or ELNB.

When discussing reliability, Ziman was careful to point out that the vast majority of knowledge gained during the operation of the material and technological mode of science is reliable (Ziman, 1991). This bold statement needs some explanation to the uninitiated. In order to guarantee high quality manufacturing, it is necessary to understand the science that underpins a process. Put simply, this means that the scientific facts, which support manufacturing, must be known, must be robust to inadvertent change and must be controlled. These facts will be assembled from the repetition of many different experiments. The large number of experiments will provide considerable statistical confidence in the validity of the facts derived. The experiments performed will cover a wide range of aspects such as the raw materials put in, the machines employed, the methods used as well as the instruments and the measurements taken during the manufacturing process. The reliability of the scientific rationale upon which these facts are based is founded upon a phrase, coined by Ziman, that believable and trustworthy science is "Public Knowledge" (Ziman, 1968).

Experiments cannot be conducted in manufacturing because of safety and then cost. Scientific facts must be gained during the research and development (R\&D) phase of manufacturing. R\&D work is small scale and is performed in a strictly controlled laboratory environment where risks are minimised, by qualified, scientific personnel. Reliable documentation of all of this work and its results used to be recorded in hard-backed laboratory notebooks. The laboratory notebook, one tool of the scientific method, and the documentation therein becomes the source of the manufacturing process, the raw material specifications, the quality control methods and the final specifications of the product. R\&D is costly and because of its multi-disciplinary nature takes many years, many people and many laboratory notebook records to complete. 
There comes a point in any business at which knowledge acquisition has to be stopped so that manufacturing can commence. Manufacture is the point at which investment can be returned through product sales. However, past tragedies with drugs means that drug manufacture is unique in that it requires approval of the manufacturing process and premises by Regulatory Agencies before any medicinal product can be made and sold to the public.

During the late 1980's and early 1990's it became self-evident that the pharmaceutical industry needed to improve its internal communications if medicinal products were to be brought to market faster than the 12 to 15 years it was taking many international companies at the time.

Other reasons for this change were:

- Increased Regulatory Agency oversight within international markets, as signified by the birth in 1990 of the International Conference on Harmonisation of Technical Requirements for the Registration of Pharmaceuticals for Human Use.

- The realisation that Total Quality Management was essential in ensuring effective development and production of medicines (Martinez-Lorente et al., 1998).

- The increased awareness of the need to manage knowledge across a variety of scientific and technological disciplines if a company's competitive edge was to be maintained as the number of international competitors with specific market knowledge grew (Sveiby, 2001).

- Improvements in personal computing enabled the paradigm shift toward better (product) knowledge management.

The role of the laboratory notebook to industry was clear. Not only was it the source of manufacturing methodology with supporting scientific data, the notebook and its contents were key evidence when claims of intellectual property rights or patient safety issues came to court for judicial evaluation and legal settlement. Unfortunately the role of a laboratory notebook with respect to the importance of its content, the uniformity of layout as a valuable database in the acquisition and development of modern manufacturing processes and knowledge, as well as a potential legal safety-net does not always seem to be a fully integrated part of formal science education (Nickla and Boehm, 2011).

\section{Context}

I have noticed over the years as a teacher that we should practise the art of enquiry more frequently with our students in order to increase their confidence in their use of the scientific method. Students often need assistance in what to look for in experiments and how to record these observations in their laboratory notebooks. When all the data is assembled, the process of enquiry needs to be encouraged through assistance with the review and self-questioning of their results collected in the laboratory environment. What is not always clear is that the term data in the preceding sentence includes the date and time of the experiment and its location, a complete list of all raw materials used with their amounts, corresponding manufacturer's name and manufacturing lot number recorded. The data will also include a description of the equipment used with maker's name, model number and serial number identification. The data will also include a step-wise account of the experiment against a time-line, concentrating on the use and duration of action verbs such as add, heat, stir, cool, filter, distil, wash, dry and any observations/ measurements associated with these "actions". Any instrumental data would need to be cross-referenced to the procedure and if possible an authorised copy of the instrumental output attached with the salient 
points highlighted and the conclusions appropriately tabulated. This list of data may not be complete. When an experiment is performed for the first time, nobody knows precisely which parameters and/or actions are important to control the results obtained in the experiment. Only when complete mastery of the process of scientific investigation is achieved will a solid foundation exist from which reliable learning (public knowledge) be gained. Only then does the experimental scientist possess a secure launch-pad for future tests either by further experimentation or comparison with literature data as confirmation or denial of the original hypothesis.

Experimental science combines a variety of learning styles. Experimental science is undertaken because the scientific community believes that you learn by doing. What is often forgotten with this tenet, because it involves communication, is that you must then record what you do, what you see and what you measure, finally reviewing these records when all the data has been collected and communicating these findings to the rest of the scientific community so that your data may become "Public Knowledge" (Ziman, 1968).

Getting students to follow a set procedure, in order to write a laboratory notebook, is hard. Making pronouncements or providing written handouts to students, which state there are certain rules that must be followed when writing a laboratory notebook, only goes so far. In industry writing a notebook is part of Good Laboratory Practice (GLP) and a Regulatory Authority requirement. GLP must be followed by R\&D employees in the pharmaceutical industry. GLP is so important that if you fail to follow it routinely and consistently, you are likely to lose your job. This result is clearly not a viable option for higher education. In addition, because the notebook requirements of scientific disciplines vary, there is not necessarily a set notebook format to follow. Each notebook format will be dictated by the specific discipline being followed or, in our case, being taught by subject experts. Nevertheless, a consistent layout should provide a framework, for students and staff alike, to populate in a manner that is effective for each specialist subject in an appropriate laboratory environment. Industry has recognised what an ELNB can provide, in order to fulfil this customisable commonality. Global pharmaceutical companies such as AstraZeneca, Genzyme, GlaxoSmithKline, Merck and Organon are already using ELNBs in their R \& D environments (Tormey, 2006).

\section{Project Initiation:}

It is in this context that, in 2007, I applied for and was awarded funding from the University of Greenwich "Dragon's Den" initiative for an ELNB pilot programme in order to:

Improve student employability, as industry was already using ELNB formats.

- Reduce turnaround times for experimental laboratory work assessment and feedback.

- Enhance adherence to Good Laboratory Practice, GLP, through the use of time stamps for data entry and any changes made to these entries.

- Create a paperless environment using university Wi-Fi connections.

- Improve academic supervision of student experimental write-up output by real time, yet external, on-line supervision of individual student ELNB's through the use of "virtual post-it notes" and added written commentary.

- Integrate a wide variety of scientific instrumental digital data output into student notebook write-ups through file import without the need for photocopying data or using glue-sticks.

- Enable "cut and paste" transfer of laboratory information into alternative coursework assignments, such as written technical reports, using intrinsic ELNB software compatibility with common Microsoft packages like Excel or Word. 


\section{Software selection and Project start-up approval:}

I sourced software that had a prolonged product lifetime, a track-record of successful usage, a wide audience of users and an ability to interface directly with existing Microsoft packages without compatibility issues. I also had to consider the university-wide constraints of cost and IT system compatibility. Suitable software was found that met all the above criteria except that it was not free. The company chosen, CambridgeSoft, was American-based and has recently been acquired by another large American, scientific instrument manufacturer of long-standing, PerkinElmer, Waltham MA, USA. CambridgeSoft's original CHEMDRAW software has been used since the start of the 1990's for chemical structure drawing for article submission to prestigious, peer-reviewed scientific journals. This start expanded into the provision of a wide range of other compatible software packages. This range of software is suitable for the chemical and bio-sciences and includes a completely user-configurable ELNB compatible with the American Drug regulatory authority's legislation - the US Food and Drug Administration Codes of the Federal Register for computer system validation, 21CFR Part 11. Furthermore, CambridgeSoft had worked hard, from the original development of their software for Apple Macintosh computers, to ensure complete compatibility with Microsoft software architecture.

Project start-up approval, like any new proposal, proved much more difficult. It was not until 2010/2011 that my School accepted the importance of laboratory work within a framework of the concept of "learning by doing" that had been suggested within the School of Chemical and Biological Sciences in the 1990's if not before my time at the university (Dewey, 1938). Today, the learning by doing approach is seen as a marketing advantage, which could raise our position within the current UK HEI science listings. Furthermore, learning by doing can be used as a key performance indicator for early career research staff. Here the target would be to more fully utilise the available undergraduate and postgraduate resources in the School of Science to create higher levels of research output. Combining project work over time from these resources could also provide proof of concept or, better define the scope of future research grant proposals.

Moreover, from my perspective, the laboratory is the ultimate in terms of a blended learning environment (Bonk et al., 2005). Laboratory work includes group and individual work, face to face teaching, IT work via the Internet, instrument use and data export to PC or other mobile device such as a tablet, laptop or smartphone, manipulative handling of materials, health and safety, auditory, visual and olfactory styles of learning all in one place.

\section{Preparing for project start-up}

\section{a) Documentation}

Laboratory manuals for the practical classes associated with course OBIO1017 were collated from a variety of office and teaching staff sources. The OBIO1017 practical classes for chemistry students can be divided into two sets of four weeks with a total of eight individual experiments per set. The second set of practical classes was chosen for the pilot. The second set of experiments from the practical class manual was personally edited into a consistent Word format that could be readily configured by the CambridgeSoft engineers into the pilot ELNB page layout for each individual experiment. The editorial process was lengthy and because of the limited time for implementation was fraught with converting prose into procedural bullet-points suitable for easy transfer to an electronic format ensuring relevant Health and Safety information was included. In addition, calculations had to be deconstructed into steps and reformatted as Excel spreadsheets so that students could more readily understand the calculations 
requested and visualise the structure of the mathematical functions used in the experiments. This "signposting" of calculation methods often helps students see how to structure future calculations in a manner similar to more formal example calculations used in physical sciences textbooks and in publisher's on-line e-resources. The built-in, sign-posted approach to calculations was suggested by CambridgeSoft during the editing period and was successfully completed prior to final ELNB configuration by the software team.

b) Software and Hardware Installation

Many university-wide IT developments were on-going during Academic Session 2010/2011. It was decided jointly by CambridgeSoft personnel and the university IT team that CambridgeSoft should use an ELNB Enterprise Cloud-computing solution for the software implementation to minimize any risks associated with in-house IT system compatibility issues. A cloud-computing solution would entail loading elementary software on to the laptops purchased by the School and prepared by the IT team at Medway for the students. It would then be possible to use the Wi-Fi capability available in the Link Laboratory situated between the Anson and Grenville buildings on the Medway campus.

c) Training and Student selection

Staff training to enable configuration of the ELNB was agreed with CambridgeSoft on a longer timetable than was foreseen for the ELNB Pilot. Such decisions would depend on the success or failure of the pilot and an evaluation of the risk-benefit ratio for the university in terms of cost, achievement of Greenwich Graduate Attributes and impact upon the student experience and student employability.

A complete cohort of students was selected for the pilot. The cohort chosen was Level 4 students all of whom bar one were enrolled on the BSc Hons Chemistry. The exception was one student enrolled on the MChem Chemistry. The students were introduced to me by the Programme Leader and given an introductory talk about the pilot its aims, its content and its assessment at the start of Term 2 of Academic Session 2010/2011. The talk was followed by a Q\&A session to discuss any student concerns. Half of the Term 2 practical element of course OBIO1017 was chosen so that a comparison could be made between more traditional methods of practical class delivery and assessment and that associated with the ELNB pilot. ELNB software usage training of these students was completed on-site at the Medway Campus by two CambridgeSoft personnel over a period of two hours.

\section{Preliminary reflections on the ELNB pilot}

Presentation of the results of the evaluation of the pilot and its comparison with more traditional methods of practical class delivery and assessment will require more space than is available here. Nevertheless, it is pertinent to provide some of the highlights and low lights experienced.

a) Lowlights

There is a cost associated with a pilot of this kind. Very simply, the cost of materials and software came to just over $£ 9 \mathrm{~K}$ for 18 students. This figure is easily translated into just over $£ 500$ for a laptop and access via cloud-computing to CambridgeSoft's ELNB software database for each student. Installation of the CambridgeSoft ELNB software in-house would be expected to cost more than this on an individual student basis. The exact figure would be negotiable.

Wi-Fi throughput capacity must be taken into account if a large class tries to log-in to software, which is available via a cloud computing solution. Simultaneous log-ins can result in severe log jams in data transfer and potentially lead to system crashes. Students were advised to log-in as they arrived to reduce these 
risks. Although difficulty with data transfer was experienced, no system crash occurred during the pilot. Cloud-computing does slow down student data transfer. Thus delays were experienced with student ELNB record updating. This meant that sometimes I, as external supervisor, was unable to see remotely what the student was writing or had written in their ELNB. The IT team had warned that this situation could occur. The IT team would have preferred a local area network for the pilot rather than Wi-Fi.

Nevertheless, one of the major advantages of an Enterprise cloud-computing solution meant that the students were able to log-in to their work from any PC, anywhere in the UK or the world for that matter, with a unique authorisation code provided to each of them by CambridgeSoft.

Early on in the trial, one student successfully deleted all of their half-day's experimental work during the data saving process. This loss was fortunately restored by CambridgeSoft engineers and the functionality, which was the root cause for the deletion, was removed from all student software applications. Although the problem did not re-occur, it proved difficult to restore the single student's faith in technology. The student openly complained that a laboratory hard-backed notebook would be their preferred medium for practical class write-ups.

Surprisingly student familiarity with Microsoft software packages such as Excel was not uniform across the class. Clearly greater emphasis on familiarisation with Microsoft software should be encouraged earlier in the Level 4 academic year if an ELNB is to be used in future.

b) Highlights

Interestingly the shortfall mentioned above spontaneously generated an Excel graphical display self-help group, which shared knowledge with the rest of the cohort and gradually overcame many of the difficulties associated with "charting" results using Excel. The spontaneous formation of a self-help group is a fine example of student-centred learning and is another good example of the blended learning available in a practical class.

Interestingly, many students used the webcam in their laptops to take pictures at various stages of their experiments. Titration end-point determination was chosen by many to photograph and often showed that students had looked for large changes of colour of the end-point indicator rather than the very subtle and often difficult to see delicate changes exhibited at the actual titration end-point. The ability to comment on this point in standard laboratory hard-backed notebook circumstances would not be possible, unless supervision was performed on a one-to-one basis. This style of supervision would be an unrealistic aim to achieve for large classes, yet it was possible to access the digital photos remotely and comment directly on the extent of over-titration in real time using the CambridgeSoft ELNB.

Despite the apparent lack of Microsoft software familiarity shown by some students in the pilot, all of them seemed much happier with the process of importing instrumental digital data either as *.pdf or photographs as *.jpeg files from other sources. The reader may be puzzled as I cannot show a screen-print of the ELNB as an example of this apparent ease. This obvious shortfall is because the ELNB pilot is over and all notebook and experimental data was converted from Cambridgesoft's cloud-server ELNB database format to Microsoft Word *.doc files at the completion of the pilot trial. Although Word documents do not portray the overall "feel" of the ELNB to the reader, I will attempt to describe this "feel" and hopefully the ease with which such data transfers can be made may become evident. 
Imagine a computer screen window divided into a number of sections. On the left-hand side of the screen is a long, vertical narrow section with the list of 8 experiments assigned to the student. On the right of this narrow section there is a bigger section which fills the screen window from below the menu bar to the bottom of the screen. At the top of this middle section are various tabs labelled Health and Safety, Procedure, Calculations, Q\&A, and Conclusions. The middle section can be best visualized as a card-index file. Each tab enables the student to access material associated with each tab heading. On the right hand side of the middle section is the final section used by the student to write-up their experimental details and to have each entry automatically time-stamped by the ELNB software.

The way this works in practice is that the student can read the health and safety tab and sign that they have both read and understood the risks associated with the experiment and that they will abide by the necessary safety precautions outlined in this section. The student can then open the Procedure tab, which has the experimental procedure written out as numbered points. The student can then annotate the righthand write-up section matching the same numbers as in the Procedure tab with automatic time-stamps for the individual entries, any observations made, any measurements requested or any alterations made post hoc. The recorded measurements can then be copied into the various calculation steps in the Excel spreadsheet(s) under the tab labelled Calculations.

Any data that arises from other sources outside of the ELNB software programme can be imported using an Import function on the software Menu bar. The data can then be inserted directly as an additional "tab" into the middle window of the ELNB along with a suitable title such as "end-point jpeg" to describe the contents of the new tab. This file import process is considerably less time-consuming than scanning instrument print-outs and then transferring scanned images. Moreover, this transfer is more professional in quality when compared to photocopy reduction of instrument non-standard paper output and then gluing the photocopy into a hard-backed notebook. The ELNB offers the ability to transfer instrument data output indirectly with a USB flash drive or directly via a university- or School-networked instrument.

The ability to interact directly with the written output of a student, to provide encouragement where brevity is being used correctly and to guide where appropriate description is evading the student is highly prized from my perspective. The organisational layout of this ELNB made assessment much easier through consistency of layout and improved legibility helped considerably. The ease with which a large amount of ELNB data can be accessed from any PC, makes marking a more pleasurable experience. There is no need to occupy Student Affairs coursework collection rooms, interact synchronously with coursework collection personnel or involve Facilities Management and porterage of weighty, hard-backed notebooks around the campus.

My overall impression of the pilot can be summarised by one student comment:

"This is the best lab book l've ever written."

\section{Preliminary Conclusions:}

The pilot ran over four weeks in March 2011. The trial shows that CambridgeSoft ELNB software works in higher education. The pilot demonstrates that an ELNB can be introduced into the School of Science and that, in the most part, it is received well by Level 4 Chemistry students in the laboratory environment. 
The pilot also demonstrates that the ELNB software chosen for this pilot is customizable for chemical sciences and available off the shelf (Crosbie 1998). Thus, CambridgeSoft software configuration would not be expected to be an issue as technology, working methods, science knowledge and teaching change. It has been shown that current teaching materials can be converted into an ELNB format and that other software packages and scientific instrument digital data output can be successfully integrated into the student experience of experimental science.

Most students found the ELNB layout eased the process of annotating laboratory work. It improved their compliance with and assessment of GLP requirements because the process of enquiry and thus data retrieval could be prompted by inserting questions into the ELNB text at points of teacher-expected change during the experiment. Photographic evidence was easy for students to add in order to support their observational claims.

In future, it can be envisaged that all student laboratory data would be held on a server and be accessible to course coordinators, Programme Leaders and External Examiners, for assessment, moderation and auditing purposes. Moreover, if ELNB usage extended across the School, all students at all levels could contribute to organised project work. At the end of an Academic Session, the body of project work could be assembled and resultant data could be collated quickly and analysed to establish trends, assess experimental errors and amend plans for future project development.

Finally the pilot demonstrated that the CambridgeSoft Enterprise Cloud-computing solution does work with the current university Wi-Fi facilities but that real-time data updating would need improvement. Possible speed improvements with a local area network alternative would have to be proven.

\section{Future Work}

The conclusions above are based upon a preliminary analysis of the pilot experience. The pilot was monitored additionally using three student questionnaires to establish:

A baseline of student experiences of practical laboratory classes prior to university

- A comparison of practical laboratory class experiences during Term 2 at university

- The student perception of the ELNB pilot

Beyond analysis of the questionnaires, a statistical comparison followed by a discussion of the assessment marks obtained during the two sets of practical classes during Term 2 will be presented at a later stage in order to establish if there is a significant difference in student achievement when using an electronic medium.

If, following these analyses the outcomes are positive, all that would remain would be to assess the riskbenefit ratio of ELNB implementation across the School of Science and to make the commitment to a modern, blended learning environment in which the ELNB could play a significant role in improving the business efficiency and employability of our students.

\section{Acknowledgements}

I should like to thank the TQEF, via the Dragons' Den initiative, for financially supporting this project.

I want to thank all of the students, who participated in this pilot, for putting up with me and providing much written and vocal feedback. I should also like to thank the current School of Science Senior Management 
Team for their support. I want to thank Nicola Coleman, Marilyn Croucher, Andy Mendham, Marilyn Talbot and Andy Tight, who prepared for and participated in the ELNB pilot.

In conclusion, I want to thank Ed de Quincey, Karen Smith and Simon Walker for their guidance. Their help was invaluable.

\section{References}

Bonk, C. J., Graham, C. R., Cross, J. and Moore, M. G. (2005). The Handbook of Blended Learning: Global Perspectives, Local Designs. 1st Edn, San Francisco, Pfeiffer in partnership with John Wiley.

Crosbie, J. (1998). [Online]. Available at: http://ame-learning.com/revolution/e-learning-services/off-theshelf/ [Accessed 30th March 2012].

Dewey, J. (1938). 'Experience and Education', 1st Edn, New York, Kappa Delta Pi Publications, New York: Macmillan.

Martínez-Lorente, A. R., Dewhurst, F. and Dale, B. G. (1998). 'Total quality management: origins and evolution of the term', The TQM Magazine, Vol. 10(5), pp.378-386.

Nickla, J.T. and Boehm, M.B., (2011), 'Proper Laboratory Notebook Practices: Protecting Your Intellectual Property', Journal of Neuroimmune Pharmacology, Vol. 6(1), pp4-9.

Sveiby, K-E, (2001). [Online]. Available at: http://www.providersedge.com/docs/km_articles/KM_-Lessons_from_the_Pioneers.pdf [Accessed 30th March 2012].

Tormey, P (2006). 'CambridgeSoft Global Account Program', Enterprise Solutions, CambridgeSoft.com, ChemBioNews, Vol. 16(3), 25.

Ziman, J. M. (1968). 'Public Knowledge: An Essay Concerning the Social Dimension of Science', Cambridge: Cambridge University Press.

Ziman, J. M. (1991). 'Reliable Knowledge: An Exploration of the Grounds for Belief in Science', Canto Original Series (1978), Cambridge: Cambridge University Press.

Ziman, J. M., (2002). Real Science: What it Is and what it Means, Cambridge: Cambridge University Press.

Ziman, J. M., (2008). Teaching and Learning about Science and Society, Cambridge: Cambridge University Press.

\section{Author Biography}

Mark Edwards is a principal lecturer in Pharmaceutical Sciences. Mark joined Greenwich in 1994 and the ILTHE in 2000. His programmes met the European Directive academic requirements for QP and an overseas demand for industry-focussed teaching. He co-authored the Medway School of Pharmacy curriculum for the RPSGB in 2003. 